\title{
A ACOLHIDA DO RECÉM-NASCIDO: A MODERNIDADE DE ALGUNS RITUAIS VIETNAMITAS ${ }^{1}$
}

\section{WELCOMING THE NEWBORN: THE MODERNITY OF SOME VIETNAMESE RITUALS}

\author{
Luong Cân-Liêm ${ }^{2}$ \\ Nguyen Thành-Châu ${ }^{3}$ \\ aLê-Thi Hong Nhung ${ }^{4}$
}

CÂN-LIÊM, L.; THÀNH-CHÂU, N.; NHUNG, L.-T. H. A acolhida do recém-nascido: a modernidade de alguns rituais vietnamitas. Rev. Bras. Cresc. Desenv. Hum., São Paulo, 2003.

\begin{abstract}
Resumo: A partir da consideração de diferenças entre a civilização ocidental e a oriental na maneira de conceber as relações entre os elementos constitutivos da cultura foram observados os processos e a construção dos processos de identificação das relações homem-mulher, adulto-criança, hierarquiasubordinação nas culturas da Ásia que estão atualmente margeando a modernidade devido à mundialização das referências culturais. O presente artigo baseou-se em observações clínicoantropológicas que mostraram que certos rituais da acolhida do recém-nascido vietnamita persistem em sua significação moderna. O artigo descreve e explica o significado tradicional de alguns destes rituais: o fio no pulso; o desenho da sobrancelha; a massagem; o processo de nomeação; a entrado do neonato no espaço domiciliar; as festas do primeiro mês e do primeiro aniversário, mostrando as alterações dentro do novo contexto.
\end{abstract}

Palavras-chave: recém-nascido vietnamita; rituais de acolhida; modernidade; tradição.

\section{MODERNIDADE E CULTURA}

A importância da cultura é ser a fonte da psique, coletiva e individual, conferindo-lhe os elementos indispensáveis de sentido e enunciando o seu lugar no mundo. A cultura prepara um espaço grupal de desenvolvimento, portador de progresso, que se chama civilização.

Existem, entre a civilização ocidental e a oriental, diferenças na maneira de conceber as relações entre os elementos constitutivos da cultura. Para dar uma rápida síntese, parece que a cultura oriental encara todas as coisas, todo acontecimento, em uma relação dialética de complementaridade (o Yin-Yang chinês e o ÂmDuong vietnamita). O que existe, existe apenas pela presença de seu complemento que especifica a diferença, a separação e a simetria. O elemento e o seu elemento complementar associado formam a entidade que instala a harmonia. A temporalidade surge como o vetor da evolução: a harmonia e o seu complemento assim emergido formulam um novo movimento que finalizam em um nova entidade, mais

1 Este artigo foi publicado, em francês, no site da Association Géza Róheim, coordenado por Patrick Fermi, no dia 24/02/2003, tendo sido autorizada a sua tradução e publicação na RBCDH pelos autores e pela Associação. http://perso.wanadoo.fr/ geza.roheim/html/luong3.htm

2 Psiquiatra, doutor em Psicologia. Associação Científica Franco-Vietnamita de Psiquiatria e de Psicologia Médica. 75 avenue d'Italie 75013 Paris, França.

3 Documentarista, EPSE Genebra, DEA-Sci. Educ. Paris V.

4 Psiquiatra, Centro de Saúde Mental da cidade de Ho-Chi-Minh. 192 quai Ham-Tru, Q.5, Hochiminh Ville, Vietnam. 
integrativa, maior, mais global. A harmonia se desenvolve em um universo einsteiniano "em expansão": os pontos que delimitavam os estados complementares necessários, e faziam avançar o movimento, tornam-se, assim, menos importantes. Tornam-se pormenores constitutivos de um conjunto amplificado.

$\mathrm{Na}$ cultura ocidental, as relações dialéticas são relações entre elementos de valor igual, rotulados como agonistas e antagonistas. O julgamento platônico do pró e do contra criou uma ordem de organização do espaço daquilo que será doravante nomeado como constitutivo do conflito. A resolução do conflito dialético, à maneira kantiana ou hegeliana, conduz à formulação de uma síntese entre elementos contrários. O aparecimento do terceiro termo unifica a contradição e produz uma economia do sistema que avança, portanto, instalando novas condições, reposicionando o pró e o contra. A discussão existirá sempre. O complementar é necessariamente contrário? Nomear o simétrico supõe o oposto que será imediatamente o antagonista? A essência das coisas é intrinsecamente silenciosa, ou um espelho daquil que lhe situa o limite? O bebê é o complementar da entidade família, ou o terceiro termo de uma síntese de dois seres que formam um casal?

Pelo que nos concerne, o recém-nascido na cultura asiática é considerado como o sujeito harmonioso da relação complementar, sexuada, de dois pais. O nascimento é o acontecimento complementar à morte, em uma sucessão cíclica do tempo, tendo a filiação e a geração como "fios vermelhos". O recém-nascido não é, ao menos na representação cultural, o terceiro ser, forçosamente olhado como

sexuado pelos pais enquanto (suposto) rival, aliado ou cúmplice. Observamos, então, muito atentamente os processos e a construção dos processos de identificação das relações de ordem (homem-mulher, adulto-criança, hierarquia-subordinação) nas culturas da Ásia, que margeiam a modernidade com a mundialização das referências culturais. O que acontece nas populações migrantes asiáticas mergulhadas na cultura ocidental emerge como uma situação de laboratório: condições experimentais de evolução para culturas em via de modernização e condições experimentais de integração que estudam, por um efeito de espelho in situ, as relações das mentalidades (para tomar um termo genérico) endo e exógenas.

Observações clínico-antropológicas mostram que certos rituais da acolhida do recémnascido persistem em sua significação moderna.

Um abordagem psicológica empírica representa um ganho em interesse se uma leitura dinâmica ajudar a compreensão da maneira de ser no mundo considerada como uma arte de viver. O alter ego constitui a fonte da alteridade cultural, da diversidade irredutível das civilizações. A cultura é uma estilização da existência.

\section{COLOCAR UM FIO NO PUNHO}

Muito cedo, ao nascer, o bebê recebe um fio, colocado no pulso, em geral trançado. Utiliza-se o mesmo fio de costura que serve para costurar as peças de tecidos usados para confeccionar uma roupa, o que o distingue do barbante para empacotar, por exemplo.

Este símbolo de ligamento5 tem vários significados em uma região onde a mortalidade infantil é grande. É importante, com efeito que, no nascimento, o fio prenda o espírito e o corpo em uma única entidade, para dar a partida a uma existência. Em geral, considera-se o espírito como resultado de uma encarnação que encontra a sua forma, - a sua formalização -, em um corpo construído a partir do corpo da mãe, ao longo da gravidez. O recém-nascido, ao nascer, tem a idade de um ano. A vida começa desde a concepção mental (no imaginário e no simbólico) dos pais. Esta vida se torna existência declarada quando a gravidez se torna

5 Attachement: tanto é apego, afeição quanto ligamento, atadura. 
visível (estar grávida). É uma noção de visibilidade que se diferencia da de vitalidade. Algumas mulheres asiáticas só se inscrevem em uma maternidade a partir do momento onde "aquilo" aparece visível (vivenciado=náuseas), e não no momento em que um teste de farmácia comprova o seu estado.

É tanto um ato de nascimento quanto de reconhecimento simbólico que os pais concedem ao recém-nascido. $\mathrm{O}$ fio preenche uma função de ligar aquilo que nós chamamos “criança real” e "criança imaginária” à criança finalmente lá, como o símbolo representável da perpetuação de uma filiação. Na religião budista, o espírito incontestavelmente tem origem no Karma informe das gerações precedentes, que o transmitem a um herdeiro merecedor. Um bebê com boa saúde, sem handicap, testemunha um bom Karma graças às realizações éticas das gerações antigas.

A evolução desta tradição se moderniza em presentes como correntes de ouro, com o nome gravado ou a gravar.

Como um gesto de vaidade, algumas mulheres usarão pulseiras, alguns homens usarão uma corrente. Os mais elegantes preferirão pulseiras de jade. Esta pedra é considerada uma representação da eternidade. Se a pulseira de pedra quebra, indica má sorte, sinal premonitório de uma infelicidade por quebra de um equilíbrio, de uma harmonia. Assim, elas desejam se enfeitar com esta pulseira apenas nas grandes solenidades, permanecendo nos cofres nos dias comuns.

\section{DESENHAR A BELEZA DO CARÁTER}

Desde os primeiros momentos, a mãe (ou a avó) traça com o caule de uma folha de bétele a linha das sobrancelhas do bebê. É bom que ela o faça com um só traço, com a mão levantada, em um gesto seguro portador da total confiança que o evento requer. A tradição indica que esta é a maneira de desenhar a futura beleza do rosto e dar os traços visíveis da personalidade da criança. Poder-se-ia dizer que é um investimento narcísico que se opera entre a mãe e a criança, sendo mais significativo ainda para as filhas. A folha de bétele se parece com a folha da árvore "bodhi", ao pé da qual Buda prega o despertar, e tem a forma estilizada de um coração.

No teatro clássico, o movimento das sobrancelhas representa a expressão dos estados de quietude e de cólera, no sentido próprio da expressão: franzir as sobrancelhas.

\section{MASSAGEAR O BEBÊ}

Nos primeiros dias, e até o bebê manifestar os seus movimentos espontâneos, recomenda-se acariciar o rosto do bebê com movimentos de alisamento e massagear o corpo inteiro, pegando, parte por parte, na mão inteira (não dizer que há uma intenção de maltrato!). Trata-se de gestos de ligadura, como para firmar os músculos e colá-los aos ossos e à pele, e conciliar as partes moles e as duras com os seus envelopes.

É espantoso constatar como o bebê vive isto olhando fixamente o manipulador. Podese acreditar que esta prática tem uma função de integração psicosensorial, uma espécie de sensualidade primitiva que assegura uma unidade psicomotora construtiva dos primeiros esquemas corporais. Este exercício pode ser feito também na água, freqüentemente no chuveiro ou por um chuveirinho no Vietnã, e na banheira quando se tem os meios. Algumas famílias passam por tipos de invólucros antes de dar a ducha ou o banho.

'Mùi', que quer dizer literalmente odor, envia a uma atmosfera de sensualidade que une. É um vocábulo empregado entre amantes. É comum o bebê reconhecer e se prender ao odor de sua mãe. Não se passa perfume no bebê. $\mathrm{O}$ equivalente ao beijo ocidental é o cheirar, que foi algumas vezes rotulado pejorativamente de atividade "psicótica" de fungar, liberando, deste modo, por estas palavras, interpretações e condutas errôneas.

O uso do talco veio com o cuidado moderno do bebê. Este pó dá uma pele branca, doce 
e perfumada. Este uso foi abandonado no Vietnã por causa do clima mas mantido no exílio por algumas mães que repetem o que conheceram outrora.

\section{DAR O NOME Á CRIANÇA}

É ainda bastante usual que a criança receba dois nomes emblemáticos apostos após o patronímico. O patronímico (exemplo: Luong, Nguy?n) é tradicionalmente colocado em primeiro lugar para marcar a ordem de filiação e a identificação com o grupo.

Colocar o pré-nome antes do nome patronímico, à maneira ocidental, impõe inverter as perspectivas das relações individuais e familiares. Dámo-nos conta de que a cultura enuncia muito cedo, deste modo, o lugar da pessoa. No mundo anglo-saxão, qualifica-se de "christian name" (nome cristão) o pré-nome colocado em primeiro lugar (first name) para assegurar uma proteção divina ou do sagrado. A esse respeito, a cultura administrativa coloca em primeiro lugar o patronímico, antes do primeiro e do segundo pré-nomes.

O primeiro nome emblemático dado à criança vietnamita serve a um uso familiar, privado. Não é sempre um nome bonito mas um qualificativo substantivado que surge segundo o acontecimento ou o vivido da família no momento em que chega o bebê. A menina de nome $D$ ? $u$, que quer dizer a semente (o feijão), ou então a "coisa colocada", terá como nome público de pessoa nhàn, que quer dizer "quietude pacífica”. Ao lado dos dois nomes de pessoa, a família designa igualmente a criança pela sua posição na fatria, por exemplo, benjamim, Út (no exemplo precedente: Út $D$ ? $u$ ). O nome recebe também uma marca pela sua relação com o ano astrológico representado por um animal (o ano de 2002 é representando pelo Cavalo).

Na tradição vietnamita, a dupla denominação servia também para enganar um gênio mal que poderia, passando por lá, levar o bebê ainda frágil, ouvindo o seu belo nome. O nome dado à criança revela, em geral, uma significação,uma qualidade moral, ou então é o nome de um elemento da natureza que a literatura fez dele um símbolo. No Vietnã, que é um país tropical, o nome Tuy?t, que quer dizer neve, é dado com referência à sua brancura como um símbolo de pureza e de limpeza, tal como a literatura de inspiração chinesa relata.

Esta dupla qualificação instala, pois, na criança a aprendizagem da marcação dos espaços privados e públicos, o sentido vivido real da família de seu lugar, e a inspiração individual como um projeto de vida no social. Freqüentemente, na adolescência, somente o nome oficial permanece ao lado do número da colocação na fatria. Este modo de proceder permite colocar uma distância ante o mundo exterior, que pode ser hostil.

Com a migração, as crianças podem conservar esta dupla nomeação com um outro uso. Os pais colocam, em primeiro, um pré-nome francês e, como segundo, um pré-nome vietnamita. O pré-nome francês é usado na escola e o nome vietnamita, na casa. Esta complementaridade instala uma forma de bilinguismo, na origem de possíveis cisões, por exemplo quando segredos de família são insinuados por meio de não-ditos.

\section{MOSTRAR E COMPREENDER O SEU ESPAÇO DOMÉSTICO}

Cada moradia tem uma alma que reflete a cultura afetiva dos lugares. O guardião testemunha dos lugares se chama Ông Táo (traduzido por gênio do lar) que vai fazer o relatório das atividades vistas e ouvidas, no Céu, no momento das festas de fim de ano.

O bebê, ao chegar em sua casa, é levado para visitar a sua moradia. Vem saudar os altares, principalmente o altar dos ancestrais, depois faz a ronda da propriedade. O pai (o pai, a mãe ou um dos avós) leva-o de um cômodo a outro como o morador que apresenta a sua casa a um recém chegado. Descreve a mobília e a disposição dos objetos como se ele fosse um adulto. Faz-se funcionar as máquinas, abremse as torneiras para que ele escute o som assim como o das janelas. No campo vietnamita, fazse 
a ronda da horta ou a visita ao túmulo familiar como a apresentá-lo à família.

Esta maneira de falar com a criança nos diferentes cômodos da casa permite-lhe registrar as diversas sonoridades de seu ambiente doméstico, prevenindo certas formas de angústia do espaço e apreendendo, provavelmente, o efeito de volume e do movimento.

\section{OS DOIS PRINCIPAIS RITUAIS: A FESTA DO PRIMEIRO MÊS E O PRIMEIRO ANIVERSÁRIO}

A festa do primeiro mês pleno é chamado igualmente de Oferendas à Lucina (Cúng $M$ ?). Preparam-se oferendas aos ancestrais e a parentela convidada partilha um festim rico e completo para assinalar o desmame do bebê, que recebe presentes, poemas, sentenças paralelas (câu d?i), roupas. Os donativos à Lucina (Lucina=deusa romana que presidia ao nascimento) podem ser compostos de doze pares de sapatos, de doze maços de bétele; ou doces ... (o número doze corresponde à comunidade dos doze deuses que moldaram o bebê no ventre materno). Outrora, o parto era em casa. Esperava-se para ir registrá-lo, algumas vezes, a festa do primeiro mês do recém-nascido. É uma maneira de diferenciar o nascimento privado da chegada no social conservando uma aparência de segredo, como uma proteção suplementar.

O aniversário do primeiro ano é a festa do fim do berço (thôi nôi). O ritual é bastante parecido com o da festa do primeiro mês. Em certas famílias, organiza-se uma primeira festa três dias depois do nascimento mais cem dias. A noção da festa do centésimo dia corresponde à representação da duração necessária a uma metamorfose: para o bebê, é a simbolização de sua presença no mundo formal (da forma visível) a partir do informe. (Para o agonizante, será a partida ou o retorno ao mundo informe, o espaço do nirvana). A partir desta festa, podese verificar, de modo não obrigatório, que a criança dorme sozinha, um sinal de uma etapa que visa amenizar a angústia da separação. A partir desta festa de fim do berço, a noção de escolha pessoal já existe para a criança, assim como a idéia de uma certa determinação dos acontecimentos a vir. Coloca-se diante dela uma superfície sobre a qual estão dispostas um certo número de objetos representativos de perspectivas de escolha do futuro: um espelho, uma caneta, um livro, uma ferramenta... Observarse-á, de um modo lúdico, a primeira, a segunda e a terceira escolhas que o bebê faz. Esta prova divinatória era mais rigorosa na tradição chinesa, encarada como uma préinscrição do destino da criança que se revela, deste modo, à família. Apresentava-se à criança objetos cortantes como símbolos de poder.

Outrora, a festa de aniversário não existia. O T?t, a festa do novo ano, é o acontecimento que permite trocar votos e desejar um ano novo de vida plena. A partir desta festa, todos adquirem um ano a mais. $\mathrm{O}$ aniversário é coletivo e este ritual assegura a identidade. Uma criança concebida e nascida em ano pleno abordará a existência melhor que aquela cuja gênese foi entre dois anos, desde a sua concepção à sua chegada no mundo. Não é bom passar o $T$ ?t no ventre materno porque isto quer dizer que o bebê foi desdobrado antes de aparecer inteiro no nascimento. Será preciso vigiar para que ele não se "cinda”. Igualmente não se visita as parturientes no dia do T't, porque ela é também “duas em uma”. A máxima para desejar uma gravidez perfeita é que "a mãe (seja) redonda e a criança quadrada" (m?tròn, com vuông) 
Luong, C.L. et al.

Refere-se ao Art. de mesmo nome, 12(2), 05-10, 2002
Rev. Bras. Cresc. Desenv. Hum., S. Paulo, 13(1), 5-10, 2003

Rev. Bras. Cresc. Desenv. Hum., S. Paulo, 2003

Abstract: Taking into account the differences between the Occidental and the Oriental civilizations with regard to the way they conceptualize the relationships between the constitutive elements of culture, the present study observed the Asian cultural processes and identification construction between man-woman, adult-child, and hierarchy-subordination. The Asian population is now bordering modernity due to the globalization of the cultural references. This article is based on clinicalanthropological observation, which shows that some rituals to welcome the Vietnamese newborn endure at the present time. The article describes and explains the traditional meaning of some of these rituals: the attachment of the wrist; the drawing of the eyebrow; the massage; the naming process; the newborn's entrance into his/her new home; the first month and the first year parties, showing some changes within the new context.

Key-words: Vietnamese newborn; welcome rituals; modernity; tradition.

Recebido em 24/02/2003

Autorização em 26/02/2003

Traduzido em 02/03/2003

Aprovado em 04/04/2003 